\title{
Avaliação da carga parasitária de helmintos e protozoários em bezerros manejados em sistema orgânico
}

\section{Strategic management of pastures to control helminths and coccidia of calves in organic system}

\author{
Jenevaldo Barbosa da Silva ${ }^{1 *}$; João Paulo Guimarães Soares²; \\ Adivaldo Henrique da Fonseca ${ }^{3}$
}

\section{Resumo}

O objetivo do presente trabalho foi avaliar a influência da eliminação de ovos de helmintos e protozoários nas fezes de bezerros mantidos em sistema orgânico de produção. De janeiro de 2008 a dezembro de 2009, foram realizados quinzenalmente exames coproparasitológicos de 18 bezerros manejados em sistema rotativo de pastagens na Embrapa Agrobiologia. Os dados médios de contagem de ovos foram submetidos ao teste de Kruskal Willis e os valores percentuais da contagem de larvas ao teste de qui-quadrado. A contagem média de ovos por grama de fezes (OPG) variou de 250 a 800 , caracterizando infecção leve a moderada. Animais com idade inferior a seis meses apresentaram OPG significativamente superiores $(\mathrm{p}<0,005)$ aos de faixa etária entre seis e doze meses. Os maiores graus de infecção foram observados no final da primavera e verão. Nos exames coprológicos foram identificados os seguintes gêneros: Haemonchus (73\%), Trichostrongylus (24\%) e Oesophagostomum (3\%). As práticas de manejo adotadas em sistema orgânico de produção foram capazes de manter os animais em níveis moderados de infecção por helmintos e protozoários, indicando que há controle parasitário pelo uso do sistema rotativo de pastos.

Palavras-chave: Gado leiteiro, Haemonchus, pastejo rotativo

\begin{abstract}
The objective of this study was to evaluate the influence of helminths eggs and protozoan oocysts elimination in calves' feces kept in organic system production. The study was conducted from January 2008 to December 2009. Coproparasitological examinations were carried biweekly of 18 calves in pastures rotating system on Embrapa Agrobiology.The egg counting average data had been submitted to the Kruskal Willis test and the larvae counting percentile values to the qui-square test. The average counting of eggs per gram of faces (EGF) varied of 250 the 800, characterizing low and moderate infection. Animals with inferior age the six months had presented superior results of EGF $(\mathrm{P}<.05)$ to the ones of between six and twelve months age. The biggest degrees of infection had been observed in the late spring and summer. In the fecal examinations was identified the following helminths: Haemonchus (73\%), Trichostrongylus (24\%) and Oesophagostomum (3\%). The practical handling adopted in organic system production had been capable to keep the animals in moderate levels of infection, being indicated that it had helmintoses control in rotating system of pastures.
\end{abstract}

Key words: Dairy cattle, Haemonchus, rotational grazing

\footnotetext{
${ }^{1}$ Doutorando na Universidade Estadual Paulista, UNESP, Jaboticabal, SP. E-mail: jenevaldo@hotmail.com

${ }^{2}$ Pesquisador da Empresa Brasileira de Pesquisa Agropecuária, EMBRAPA, Brasília, DF. E-mail: jp.soares@cpac.embrapa.br

${ }^{3}$ Prof. da Universidade Federal Rural do Rio de Janeiro, UFRRJ, Seropédica, RJ. E-mail: adivaldo@ufrrj.br

* Autor para correspondência
} 


\section{Introdução}

A busca por alimentos orgânicos encontra-se em franca expansão, tornando-se um importante mercado consumidor. Este fato tem incentivado os produtores de todo mundo, principalmente nos países agroexportadores a adotarem tecnologias sustentáveis dos recursos produtivos, com preservação e ampliação da biodiversidade, visando atender estes consumidores (D'ALMEIDA, 2005). No Brasil, a busca por produtos orgânicos tem crescido ao redor de $10 \%$ ao ano, fato que evidencia o desejo dos consumidores em comprar leite proveniente de animais criados em sistemas que promovam o bem-estar animal, e que sejam sustentáveis e ambientalmente corretos (D'ALMEIDA, 2005). O leite orgânico produzido alcança até três vezes o valor do produto convencional, ao consumidor, principalmente na região sudeste, onde os consumidores possuem maior poder aquisitivo (AROEIRA; FERNANDES, 2001).

Apesar de possuir grande potencial para o desenvolvimento de produtos orgânicos de origem animal, o País ainda apresenta produção incipiente, não chegando a $0,02 \%$ da oferta nacional, em torno de 6,8 milhões de litros em 2010 (SOARES et al., 2011). Diferentes fatores contribuem para esta pequena produção, como a carência de pesquisas enfocando a alimentação, o padrão racial e os cuidados sanitários do rebanho, especialmente no que diz respeito às infecções por helmintos gastrintestinais (HÖGLUND; SVENSSON; HESSLE, 2001).

Para o controle racional e sustentável desses organismos gastrintestinais em animais mantidos em sistema orgânico, é necessário o conhecimento sobre epidemiologia dos parasitos, manejo de pastagens, controle sanitário do ambiente de produção e dos animais (LARSEN, 2002). O monitoramento dos parasitos gastrintestinais em rebanhos leiteiros, principalmente nos animais jovens e mais susceptíveis a infestações parasitárias é de grande relevância. Quando os animais são mantidos em sistemas de pastejo contínuo, ou seja, sem utilização de pastagens subdivididas em piquetes, os animais tornam-se mais vulneráveis as re-infecções, além de atuarem como fontes de reinfestações das pastagens (PIMENTEL NETO et al., 2002).

O combate aos helmintos nos países de clima tropical tem sido realizado, a partir do uso intensivo de compostos anti-helmínticos (CATTO et al., 2005). Embora essas drogas tenham eficácia comprovada, a ausência de protocolos adaptados para as regiões tropicais aliado ao uso inadequado das bases terapêuticas, tem provocado o aumento do custo de produção. Alem disso, contribuem para o surgimento de estirpes resistentes, aumento de contaminação das fontes de água e de alimentos e a presença de resíduos de droga na carne e nos produtos lácteos, solicitando estudos de métodos alternativos de controle (COPPIETERS et al., 2009; OLIVEIRA et al., 2009).

Embora o sistema de manejo de pastagens seja usado como solução simples e rápida para o controle de nematóides, ainda não existe estudo de controle de nematóides em sistema de pastejo sem o uso de anti- helmínticos (BIANCHIN et al., 2007). Segundo Catto et al. (2009), apesar de produtores e técnicos ligados à pecuária orgânica o recomendarem, não há resultados experimentais ou estudos de caso que tenham demonstrado o seu efeito no controle dos nematóides gastrintestinais de bovinos no Brasil.

Na pecuária convencional, o controle de parasitos gastrintestinais é muitas vezes baseado na utilização estratégica de anti-helmínticos (NANSEN, 1993). A regulamentação da LEI 10831 que caracteriza o sistema orgânico de produção agropecuário nacional, foi instituída pelo DECRETO $\mathrm{n}^{\circ}$ 6323, e através da Instrução normativa $n^{\circ} 46$ (BRASIL, 2011). Estas normas para produção animal proíbem o uso profilático de anti-helmínticos, o que implica que o rebanho somente pode ser tratado com 
medicamentos fitoterápicos, extratos vegetais e homeopáticos, onde toda a terapêutica utilizada fora disto deve ser registrada para eventuais orientações de produção.

O objetivo do presente trabalho foi avaliar a influência da eliminação de ovos de helmintos e protozoários nas fezes de bezerros mantidos em sistema de produção orgânico.

\section{Material e Métodos}

O estudo foi realizado de janeiro de 2008 a dezembro de 2009, no Sistema Integrado de Produção Orgânico (SIPA) Fazendinha Agroecológica Km 47 - Convênio entre a Empresa Brasileira de Pesquisa Agropecuária (Embrapa Agrobiologia)/ Universidade Federal Rural do Rio de Janeiro (UFRRJ)/Empresa de Pesquisa Agropecuaria do Estado do Rio de Janeiro (PESAGRO-RIO), situado na microrregião Metropolitana da Cidade do Rio de Janeiro. As análises coproparasitológicas foram realizadas no Laboratório de Doenças Parasitárias, Departamento de Epidemiologia e Saúde Pública, Instituto de Veterinária da UFRRJ.

O SIPA é uma área de pesquisa e produção em Agricultura Orgânica, criada no ano 1993, implantado numa área de aproximadamente 70ha, situado na latitude $22^{\circ} 45^{\prime} \mathrm{S}$, longitude $43^{\circ} 41^{\prime} \mathrm{W}$ e altitude de 33 metros. Segundo a classificação de Köppen o clima da região pertence à classe AW, caracterizado por inverno seco e verão chuvoso e quente, com precipitação anual de $1300 \mathrm{~mm}$, inverno pouco pronunciado; temperatura média anual de $24{ }^{\circ} \mathrm{C}$ e umidade relativa do ar de $70 \%$.

Foram acompanhados quizenalmente todos os bezerros do plantel, destinado a produção de leite, desde o nascimento até o primeiro ano de idade. O número de animais variou de 15 a 20, sendo o número médio igual a 18 . Os bezerros eram mestiços (Holandês x Zebu) com grau de sangue variando de 1/2 a 5/8 Gir. Após o nascimento todos os bezerros permaneciam com a vacas, durante a ordenha, até aproximadamente 3 meses de idade, conforme recomendações de manejo orgânico previsto na Instrução Normativa 46 (BRASIL, 2011).

Para o manejo alimentar, os bezerros de zero a dois meses de idade permaneciam em bezerreiro próximo ao estábulo somente no período noturno. Durante todo o dia eram manejados soltos numa pequena área de pastagem com capim Coastcross (Cynodon dactylon L.pers., Coastcross) subdivididas em dois piquetes de $60 \mathrm{~m}^{2}$ cada, sendo alternados a cada cinco dias. Já os bezerros de dois a seis meses de idade eram manejados numa área 0,47 ha, composta por uma pastagem de capim Estrela Africana (Cynodon nlenfuensis, Vanderyst) consorciado com as leguminosas Araquis (Arachis pintoi), Desmodium (Desmodium ovalifolium) e Estilosantes (Estylosanthes guyanensis) subdivididas em 4 piquetes de $1175 \mathrm{~m}^{2}$, manejados em sistema rotativo com 8 dias de pastejo e 42 dias de descanso.Durante este período os animais foram mantidos sob uma densidade média de $3 \mathrm{UA} / \mathrm{ha}$.

Os bezerros com idade entre 6 a 12 meses pastejavam em conjunto com o restante do rebanho, constituído por vacas em lactação e secas perfazendo um total de 31 animais nesta pastagem. A área total da pastagem utilizada foi de 7,8ha divididos em seis piquetes de 1,3 ha, composta por capim Tanzânia (Panicum maximum cv. Tanzânia) em consórcio com Calopogônio (Calopogonium mucunoides). O sistema de pastejo empregado foi o rotativo, com sete dias de pastejo, 42 dias de descanso e taxa de lotação de 2UA/ha no período das águas e 1UA/ha no período chuvoso. Em todas as áreas utilizadas de pastagens o número de animais por área e redução do período de descanso dos piquetes era feito conforme disponibilidade de produção de biomassa da pastagem.

Durante a estação seca do ano (abril a setembro) além da pastagem, a suplementação aos animais de 0-6 meses foi feito com fornecimento ad libitum de feno de Gliricidia (Gliciricia sepium); para os animais de 6 a 12 meses com cana-de-açúcar 
(Saccharum officinarum) em consórcio com o Guandu (Cajanus cajan) e com capim elefante (Pennisetum purpureum, Schum, cv cameroom) em consórcio com o Siratro (Macropitilium atropurpureum), picados no cocho diariamente.

Foram realizadas coletas de amostras fecais diretamente da ampola retal de cada animal a cada quize dias. Foram realizadas contagens de ovos por grama de fezes (OPG), segundo a técnica McMaster descrita por Gordon e Whitlock (1939). Para recuperação e identificação de larvas das fezes utilizou-se a técnica modificada de coprocultura descrita por Ueno e Gonçalves (1998). Contaram-se todos os ovos de helmintos e oocistos encontrados. Porém, ênfase maior foi dada aos nematóides pertencentes à superfamília Trichostrongyloidea, devido à sua distribuição cosmopolita e alta patogenicidade.

Os dados referentes a contagem de ovos nas fezes foram inicialmente submetidos ao teste de Kolmogorov-Smirnov para verificar se estes apresentavam distribuição normal. Posteriormente, a fim de normalizá-los os mesmos foram transformados em $\log 10\left(2{ }^{`}\right.$ count +1$)$. Porém, mesmo após a transformação, os dados permaneceram não normais, sendo então submetidos ao teste não paramêtrico de KrusKal Willis a 5\% de significância. Os dados percentuais referentes a cultura de larvas foram analisados através do teste de qui-quadrado a 5\% de significância. A associação entre as variáveis dependentes, contagem de ovos e oocistos, com as variáveis independentes, idade e estação do ano, foi feita através de regressão linear simples. Os procedimentos estatísticos foram realizados com o auxílio do programa Rstudio, versão 2.12.2.

\section{Resultados e Discussão}

Os resultados dos exames coproparasitológicos revelaram helmintos pertencentes às seguintes superfamílias: Trichostrongyloidea, Trichuroidea e Rhabditoidea, além de Oocisto do protozoario Eimeria spp. (Tabela 1).

Durante todo estudo os bezerros apresentaramse infectados predominantemente por helmintos pertencentes à superfamília Trichostrongyloidea. A contagem média do OPG dos animais variou de 250 a 800 (Tabela 1). Estes resultados corroboram com os de Höglund, Svensson e Hessle (2001) que avaliaram bezerros mantidos em sistema de produção orgânica.Embora tenham encontrado animais com elevado grau de parasitismo, observaram que na maioria das amostras fecais $(98,6 \%)$ a contagem de ovos do nematóide da superfamília Trichostrongyloidea foram inferiores a 500 OPG, classificando-o como infecção baixa e moderada.

A espécie Strongyloides papillosus, apresentou contagem de ovos nas fezes variando de 0 a 150 . Foi observado maior parasitismo nos animais com idade inferior a quatro meses, embora não significativo $(\mathrm{p}>0,05)$. Durante todo estudo nenhum animal com idade superior a seis meses apresentou infecção alta, ao passo que seis animais com menos de seis meses foi identificado alto grau de parasitismo. Estes resultados corroboram os achados de Fonseca, Duque e Britto (1994) que observaram em seus estudos que animais com idade inferior a quatro meses são mais parasitados por S. papillosus.

Para a espécie Trichuris spp., observou-se baixo parasitismo, com média de 10 OPG. Estes resultados demonstram que a especie não constitui fator de risco importante para a saúde dos animais estudados, visto que além do baixo parasitismo, poucos animais apresentaram eliminação de ovos nas fezes. Estes resultados provavelmente se devam ao longo periodo pré-patente deste helminto, sendo observado parasitismo elevado apenas nos animais mais velhos do rebanho. 
Tabela 1. Médias mensais da contagem de ovos de helmintos e oocistos em bezerros mantidos sob sistema de produção orgânico de janeiro de 2008 a dezembro de 2009.

\begin{tabular}{ccccc}
\hline Meses & Trichostrongyloidea & Rhabditoidea & Trichuris & Eimeria spp \\
\hline Jan & 540 & 0 & 0 & 0 \\
Fev & 700 & 40 & 0 & 100 \\
Mar & 425 & 150 & 0 & 80 \\
Abr & 300 & 180 & 20 & 100 \\
Mai & 300 & 60 & 0 & 100 \\
Jun & 340 & 20 & 20 & 150 \\
Jul & 321 & 60 & 0 & 80 \\
Ago & 373 & 70 & 20 & 210 \\
Set & 375 & 110 & 20 & 140 \\
Out & 475 & 120 & 20 & 90 \\
Nov & 475 & 0 & 0 & 50 \\
Dez & 550 & 40 & 0 & 100 \\
\hline Média & $\mathbf{4 3 1}$ & $\mathbf{8 1}$ & $\mathbf{1 0}$ & $\mathbf{1 0 5}$ \\
\hline
\end{tabular}

Fonte: Elaboração dos autores.

A eliminação de oocistos de Eimeria spp. variou de 0 a 10 . Estes resultados corroboram os de Höglund, Svensson e Hessle (2001) que avaliaram o parasitismo gastrintestinal em bezerras mantidas em fazendas orgânicas. Estes autores não observaram nenhum caso clínico de coccidiose, atribuindo os resultados ao manejo das pastagens e ao estado nutricional dos animais.

No presente trabalho, os animais jovens não eram mantidos juntos aos animais adultos, visando evitar a infecção dos bezerros por oocistos permanentemente eliminados pelos animais adultos. No Brasil, estudos mostraram que bebedouros, comedouros e pastagens contaminados têm grande influência na infecção dos animais jovens, principalmente em criação a pasto, onde estes são facilmente contaminados com fezes de animais adultos infectados, favorecendo o aparecimento da parasitose (FABER et al., 2002).

Quando analisado os dois anos estudados, não foi observada diferença entre as médias mensais das contagens de ovos nos anos de 2008 e 2009 (Figura 1). Os resultados obtidos nos meses de novembro, dezembro, janeiro e fevereiro, quando comparados com os demais meses do ano apresentaram diferença significativa $(p<0,05)$ tanto em 2008 quanto em 2009. Esta diferença, provavelmente esta associada às condições climáticas mais favoráveis ao desenvolvimento dos estádios de vida livre dos helmintos durante estes meses.

Embora, os resultados médios da contagem de OPG do rebanho demonstrem niveis de infecção moderada, foi observado nos animais com idade inferior a seis meses valores elevados (Figura 2). Quando analisado os resultados da contagem de OPG apenas dos animais com idade inferior a seis meses, observou-se que 50\% destes apresentaram infecção moderada e 19\% infecção alta. Enquanto que na avaliação apenas dos animais com idade superior a seis meses demonstrou que 76\% apresentaram infecção leve, 19\% infecção moderada e 5\% infecção alta . Estes resultados fortalecem os resultados de Correa et al. (2001) que concluíram que a partir dos três meses de idade deve-se monitorar com maior cuidado as verminoses, as quais acometem os bovinos jovens até os dois anos, sendo que este problema é mais severo nos animais jovens, principalmente nos primeiros meses de vida. 
Figura 1. Distribuição sazonal das contagens médias de ovos de helmintos da superfamilia Trichostrongyloidea em bezerros mestiços (Holandês x Zebu) mantidos sob sistema de produção orgânico de janeiro de 2008 a dezembro de 2009. A comparação das médias mensais das contagens de ovos nas fezes foi realizada pelo teste de Kruskal willis a $5 \%$ de significância.

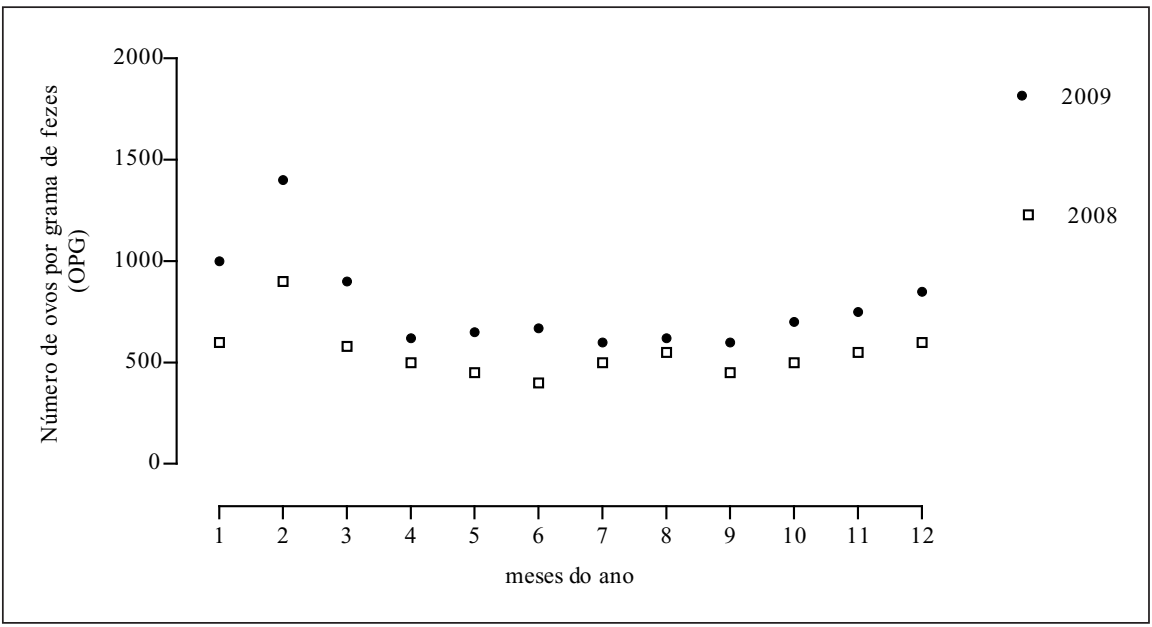

Fonte: Elaboração dos autores.

A baixa contagem de OPG observada neste estudo, mesmo sem uso de anti-helmínticos convencionais, pode ser parcialmente creditada ao manejo das pastagens e estado nutricional dos animais. A manutenção dos bezerros em pastagens descontaminadas combinada com a suplementação volumosa durante a estação seca do ano, provavelmente aumentou a resistência orgânica dos animais, contribuindo para reduzir a infecção por helmintos. Estes resultados corroboram Höglund, Svensson e Hessle (2001) que concluiram que a suplementação animal durante o período seco do ano e a utilização de piquetes exclusivos para bezerros fez com as contagens de OPG diminuíssem significativamente.

Os valores médios estacionais da contagem de OPG durante as quatro estações do ano estão representados na Tabela 2.

Figura 2. Médias mensais de ovos de trichostrongilídeos em bezerros mantidos em sistema de produção orgânica de janeiro de 2008 a dezembro de 2009. A comparação entre as médias mensais das contagens de ovos foi realizada pelo teste de Kruskal willis a significância de 5\%.

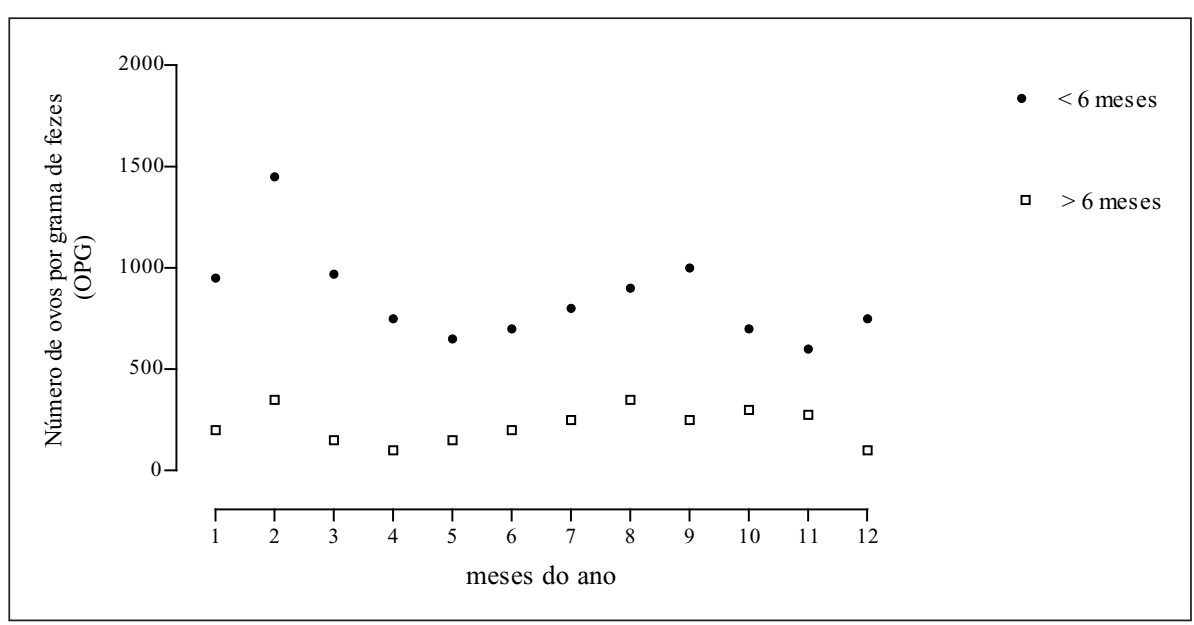

Fonte: Elaboração dos autores. 
Tabela 2. Variação Estacional das contagens médias do número de OPG em bezerros mestiços (Holandês x Zebu) mantidos sob sistema de produção orgânico na Embrapa Agrobiologia, janeiro de 2008 a dezembro de 2009. A comparação das médias mensais das contagens de ovos nas fezes foi realizada pelo teste de Kruskal willis a 5\% de significância.

\begin{tabular}{lcccc}
\hline Estação do ano & Verão & Outono & Inverno & Primavera \\
\hline 2008 & $620 \pm 125.2^{\mathrm{Aa}}$ & $370 \pm 900,8^{\mathrm{Ba}}$ & $400 \pm 125,7^{\mathrm{Ba}}$ & $610 \pm 190,2^{\mathrm{Aa}}$ \\
2009 & $500 \pm 99,8^{\mathrm{Ab}}$ & $290 \pm 124,8^{\mathrm{Ba}}$ & $320 \pm 112,6^{\mathrm{Ba}}$ & $530 \pm 182,3^{\mathrm{Aa}}$ \\
Média & 560 & 330 & 360 & 520 \\
\hline
\end{tabular}

Letras maiúsculas desiguais na linha e maiusculas na coluna representam diferença significativa ao nível de $5 \%$ de significância pelos testes de Kruskal willis a 5\% de significância.

Fonte: Elaboração dos autores.

Não foi observada diferença significativa ( $>0,05)$ na contagem média de OPG quando foram comparadas as estações do ano de 2007 e 2008. Em ambos os anos, as maiores eliminações de OPG foram observadas no final da primavera e verão. Estes resultados corroboram Pimentel Neto e Fonseca (2002) e Araújo et al. (2005), que observaram durante o verão os maiores picos parasitários. Esses autores concluíram que o elevado grau de parasitismo durante a primavera e o verão é decorrente das condições climáticas serem adequadas ao desenvolvimento de estádios larvares dos helmintos no ambiente. Ao passo que no inverno, a baixa precipitação nas regiões de baixada do estado do Rio de Janeiro, contribuem para a diminuição do potencial biótico dos helmintos.

Os resultados da coprocultura mostram a predominância de três gêneros de nematóides da superfamília Trichostrongyloidea: Haemonchus (73\%), Trichostrongylus (24\%) e Oesophagostomum (3\%) (Figura 3). Os resultados observados neste estudo foram similares aos encontrados por Silva, Fagundes e Fonseca (2011) em caprinos na mesma região. Estes autores observaram que, durante todo o estudo a prevalência do gênero Haemonchus foi sempre superior a $70 \%$, sendo o gênero Trichostrongylus o sengundo grupo mais prevalente.

Figura 3. Percentuais médios de larvas infectantes em coprocultura de bezerros mestiços (Holandês x Zebu) mantidos sob sistema de produção orgânico na Embrapa Agrobiologia, janeiro de 2008 a dezembro de 2009. A comparação das frequências mensais das larvas nas fezes foi realizada pelo teste de Qui-quadrado a 5\% de significância.

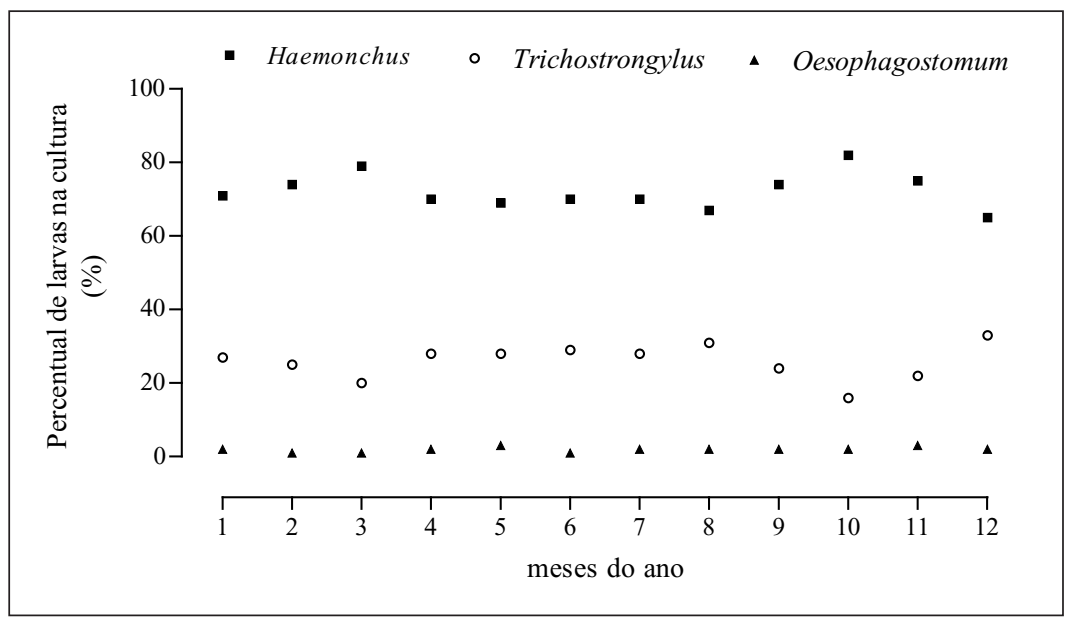

Fonte: Elaboração dos autores. 
Não foi observada diferença significativa $(p>0,05)$ entre a eliminação de ovos de helmintos quando confrontado os valores mensais. Porém, quando analisados por estação, observou-se aumento significativo $(\mathrm{p}<0,05)$ do gênero Trichostrongylus e redução do gênero Haemonchus no periodo mais seco do ano. Estes resultados corroboram Pimentel Neto e Fonseca (2002) que observaram população de Trichostrongylus com crescimento limitado pela população de Haemonchus e cogitaram a possibilidade de haver competição no nível de hospedeiro e também pelo fato de que as larvas de Trichostrongylus serem mais resistentes no ambiente sob condições adversas.

O sistema de manejo empregado para bezerros leiteiros de 0 a 12 meses em sistema orgânico de produção é capaz de manter a maioria dos bezerros com nível de infecção leve a moderada onde a carga parasitária não causa doença clínica nos animais. Porém, o número significativo de animais com idade inferior a seis meses apresentaram infecção alta, indicando que o sistema ainda e dependente de ajustes para o futuro. Assim, o monitoramento deve ser constante para prevenção de possíveis surtos de helmintoses em bezerros mantidos em sistema de produção orgânica de leite, sobretudo os com idade inferior a seis meses, principalmente durante as estações de primavera e verão.

\section{Agradecimento}

A Embrapa Agrobiologia por ceder a área e os animais para o estudo. Ao CNPq e a FAPERJ pelo apoio financeiro aos projetos desenvolvidos na Embrapa.

\section{Referências}

ARAÚJO, R. N.; LIMA, W. S. Infecções helmínticas em um rebanho leiteiro na região Campo das Vertentes de Minas Gerais. Arquivo Brasileiro de Medicina Veterinária e Zootecnia, Belo Horizonte, v. 57, p. 186193, 2005. Suplemento 2.
AROEIRA, L. J. M.; FERNANDES, E. N. Produção orgânica de leite: um desafio atual. Informe Agropecuário, Brasília, v. 22, n. 211, p. 53-57, 2001.

BIANCHIN, I.; CATTO, J. B.; KICHEL, A. N.; TORRES JÚNIOR, R. A. A.; HONER, M. R. The effect of the control of endo and ectoparasites on the weight gains in crossbred cattle (Bos taurus x Bos indicus) in the central region of Brazil. Tropical Animal Health and Production, Midlothian, v. 39, n. 4, p. 287-296, 2007.

BRASIL. Instrução normativa ${ }^{\circ} 46$, de 06 de outubro de 2011. Lei no 10831, de 23 de dezembro de 2003. Diário Oficial [da] República Federativa do Brasil. Poder Executivo, Brasília, DF, 06 Outubro. 2011. Seção 1, p. 8.

CATTO, J. B.; BIANCHIN, I.; SANTURIO, J. M.; FEIJÓ, G. L. D.; KICHEL, A. N.; SILVA, J. M. Sistema de pastejo, rotenona e controle de parasitas: efeito sobre o ganho de peso e níveis de parasitismo em bovinos cruzados. Revista Brasileira de Parasitologia Veterinária, Jaboticabal, v. 18, n. 4, p. 37-43, 2009.

CATTO, J. B.; BIANCHIN, I.; TORRES JUNIOR, R. A. A. Efeitos da everminação de matrizes e de bezerros lactentes em sistema de produção de bovinos de corte na região de Cerrado. Pesquisa Veterinária Brasileira, Seropédica, v. 3, n. 1, p. 188-194, 2005.

COPPIETERS, W.; MES, T. H. M.; DRUET, T.; FARNIR, F.; TAMMA, N.; SCHROOTEN, C.; CORNELISSEN, A. W. C. A.; GEORGES, M.; PLOEGER, H. W. Mapping QTL influencing gastrointestinal nematode burden in Dutch Holstein- Friesian dairy cattle. BMC Genom. London, v. 10, n. 1, p. 96-109, 2009.

CORREA. F. R.; SHILD, A. L.; MENDEZ, M. C.; LEMOS, R. A. A. Doenças de ruminantes e equinos. São Paulo: Varela, 2001. v. 2, 574 p.

D'ALMEIDA, T. N. Bem-estar animal x segurança alimentar. Higiene Alimentar, Itapetininga, v. 19, n. 132, p. 15-17, 2005.

FABER, J. E.; KOLLMANN, D.; HEISE, A.; BAUER, C.; FAILING, K.; BURGER, H. J.; ZAHNER, H. Eimeria infections in cows in the parturente phase and their calves: oocyst excretion and levels of specific serum and colostrum antibodies. Veterinary Parasitology, Amsterdam, v. 104, n. 2, p. 1-17, 2002.

FONSECA, A. R.; DUQUE, N. A.; BRITTO, M. S. M. Efeitos das infecs;oes natural e experimental por Strongyloides papillosus em bezerros. Arquivo Brasileiro de Medicina Veterinaria e Zootecnia, Belo Horizonte, v. 46, n. 2, p. 111-119, 1994. 
GORDON, H. M. C. L.; WHITLOCK, H. V. A new technique for counting nematode eggs in shep faeces. Journal Council Sceinci Industrial Research Australian, Melbourne, v. 12, n. 1, p. 50-52, 1939.

HÖGLUND, J.; SVENSSON, C.; HESSLE, N. Field survey on the status of internal parasites in calves on organic dairy farms in southwestern Sweden. Veterinary Parasitology, Amsterdam, v. 99, n. 2, p. 113-128, 2001.

LARSEN, M. Biological control in a global perspective - a review with emphasis on Duddingtonia flagrans. In: FAO. ANIMAL PRODUCTION AND HEALTH DIVISION. BIOLOGICAL CONTROL OF NEMATODE PARASITES OF SMALL RUMINANTS IN ASIA, 1., 2002, Rome. Proceedings... Rome, Italy: FAO, 2002. 104 p.

NANSEN, P. Current and future prospects for control of ostertagiasis in northern Europe - examples from Denmark. Veterinary Parasitology, Amsterdam, v. 46, n. 1-4, p. 3-21, 1993.

OLIVEIRA, M. C. S.; ALENCAR, M. M.; CHAGAS, A. C. S.; GIGLIOTI, R.; OLIVEIRA, H. N. Gastrointestinal nematode infection in beef cattle of different genetic groups in Brazil. Veterinary Parasitology, Amsterdam, v. 166, n. 3-4, p. 249-254, 2009.
PIMENTEL NETO, M.; FONSECA, A. H. Epidemiologia das helmintoses pulmonares e gastrintestinais de bezerros em região de baixada do Estado do Rio de Janeiro. Pesquisa Veterinária Brasileira, Seropédica, v. 22, n. 4, p. 148-152, 2002.

SILVA, J. B.; FAGUNDES, G. M.; FONSECA, A. H. Dynamics of gastrointestinal parasitoses in goats kept in organic and conventional production systems in Brazil. Small Ruminants Research, Thessaloniki, v. 98, n. 2, p. 35-38, 2011.

SOARES, J. P. G.; AROEIRA, L. J. M.; FONSECA, A. H. F.; FAGUNDES,G. M.; SILVA, J. B. Produção orgânica de leite: desafios e perspectivas. In: MARCONDES, M. I.; VELOSO, C. M.; GUIMARÃES, J. D.; ANDRADE, F. L.; PRADOS, L. F.; AMORIM, L. S.; FERNANDES, L. S.; MACHADO, M. G.; CARDOSO, W. L. (Org.). In: SIMPÓSIO NACIONAL DE BOVINOCULTURA LEITEIRA, 3.; SIMPÓSIO INTERNACIONAL DE BOVINOCULTURA LEITEIRA, 1., 2011, Viçosa. Anais... Viçosa: Suprema Gráfica e Editora, 2011, v. 1, p. 13-43.

UENO, H.; GONÇALVES, P. C. Manual para diagnóstico das helmintoses de ruminante. 4. ed. Tókio: Japan International Cooperation Agency, 1998. 143 p. 
